\title{
BMJ Open Cohort profile: the STOP HIV/AIDS Program Evaluation (SHAPE) study in British Columbia, Canada
}

\author{
Andrea Bever (D) , ${ }^{1}$ Kate Salters, ${ }^{1,2}$ Clara Tam, ${ }^{1}$ D M Moore, ${ }^{1,3}$ Paul Sereda, ${ }^{1}$ \\ Lu Wang, ${ }^{1}$ Tim Wesseling, ${ }^{1}$ Sean Grieve, ${ }^{1}$ Brittany Bingham, ${ }^{4}$ Rolando Barrios ${ }^{1,3,5}$
}

To cite: Bever A, Salters $K$, Tam C, et al. Cohort profile: the STOP HIV/ AIDS Program Evaluation (SHAPE) study in British Columbia, Canada. BMJ Open 2020;10:e033649. doi:10.1136/ bmjopen-2019-033649

- Prepublication history for this paper is available online. To view these files, please visit the journal online (http://dx.doi org/10.1136/bmjopen-2019033649).

Received 15 August 2019 Revised 06 March 2020 Accepted 16 April 2020

Check for updates

(c) Author(s) (or their employer(s)) 2020. Re-use permitted under CC BY-NC. No commercial re-use. See rights and permissions. Published by BMJ.

${ }^{1}$ British Columbia Centre for Excellence in HIV/AIDS, Vancouver, British Columbia, Canada

${ }^{2}$ Faculty of Health Sciences, Simon Fraser University,

Burnaby, British Columbia,

Canada

${ }^{3}$ University of British Columbia, Vancouver, British Columbia, Canada

${ }^{4}$ Aboriginal Health Program, Vancouver Coastal Health Authority, Vancouver, British Columbia, Canada

${ }^{5}$ Vancouver Community Health Services, Vancouver Coastal Health, Vancouver, British Columbia, Canada

Correspondence to

Dr Kate Salters;

ksalters@cfenet.ubc.ca

\section{ABSTRACT}

Purpose The Seek and Treat for Optimal Prevention of HIV/AIDS (STOP HIV/AIDS) Program Evaluation (SHAPE) study is a longitudinal cohort developed to monitor the progress of an HIV testing and treatment expansion programme across the province of British Columbia (BC). The study considers how sociostructural determinants such as gender, age, sexual identity, geography, income and ethnicity influence engagement in HIV care.

Participants Between January 2016 and September 2018, 644 BC residents who were at least 19 years old and diagnosed with HIV were enrolled in the study and completed a baseline survey. Participants will complete two additional follow-up surveys (18 months apart) about their HIV care experiences, with clinical follow-up ongoing. Findings to date Analyses on baseline data have found high levels of HIV care engagement and treatment success among SHAPE participants, with $95 \%$ of participants receiving antiretroviral therapy and $90 \%$ having achieved viral suppression. However, persistent disparities in HIV treatment outcomes related to age, injection drug use and housing stability have been identified and require further attention when delivering services to marginalised groups. Future plans Our research will examine how engagement in HIV care evolves over time, continuing to identify barriers and facilitators for promoting equitable access to treatment and care among people living with HIV. A qualitative research project, currently in the formative phase, will compliment quantitative analyses by taking a strengths-based approach to exploring experiences of engagement and re-engagement in HIV treatment among individuals who have experienced delayed treatment initiation or treatment interruptions.

\section{INTRODUCTION}

Modern treatment for HIV, antiretroviral therapy (ART), has been shown to greatly reduce HIV-related morbidity and mortality. ${ }^{1-3}$ The public health benefit of ART uptake and sustained adherence was first recognised in 2006 with the publication of mathematical models indicating that reduction in community viral load would prevent transmission and, subsequently, new cases of HIV. ${ }^{4}$ Since then mounting evidence based on clinical trials, cohort and population-based

\section{Strengths and limitations of this study}

- The Seek and Treat for Optimal Prevention of HIV/ AIDS Program Evaluation (SHAPE) study collects in-depth data concerning the experiences and perspectives of people living with HIV (PLWH) in order to improve understanding of barriers and facilitators to linkage and retention in care. Findings will be used to inform policy and interventions for addressing inequities in HIV healthcare.

- Community-engaged research methods are integrated throughout the study. For example, peer research associates are involved in all phases of research from planning to data collection, analysis and knowledge dissemination.

- Purposive sampling was employed to obtain a sample that is representative of key sociodemographic characteristics of PLWH in the province of British Columbia; however, challenges were experienced in reaching certain recruitment targets such as targets for young adults and mid-higher income groups.

- SHAPE participants were overwhelmingly engaged in HIV care at baseline, which may reflect sampling bias. Individuals who face the greatest barriers to accessing HIV care are likely to experience similar barriers to involvement in research, and therefore, to be under-represented in our cohort.

studies has led to wide spread, international support for the concept of HIV treatment as prevention. $^{5-8}$

In 2010, the Seek and Treat for Optimal Prevention of HIV/AIDS (STOP HIV/AIDS) Program was initiated as a pilot intervention by the British Columbia (BC) Ministry of Health and the BC Centre for Excellence in HIV/AIDS. At this time, it was estimated 11700 individuals living in BC were living with HIV, with 6.6 new HIV diagnoses per 100000 population (300 cases). ${ }^{9}$ In order to implement the principles of treatment as prevention in public health practice, the pilot intervention aimed to expand access to HIV testing and treatment to all clinically eligible individuals in two cities disproportionately 
impacted by the HIV/AIDS epidemic in the province of BC: Vancouver and Prince George. In 2013, the STOP HIV/AIDS Program was expanded throughout the province. ${ }^{910}$ As the STOP HIV/AIDS Program expands access to ART in BC, it is critical to monitor and evaluate sociostructural determinants of HIV health outcomes and respond to disparities in engagement in care; failure to do so could reinforce health inequities among people living with HIV (PLWH).

Despite availability of fully subsidised HIV healthcare and the optimisation of treatment and testing since 2010 in $\mathrm{BC}$, inequities in treatment access and retention persist, particularly among structurally marginalised populations. Women, Indigenous peoples, people who inject drugs (PWID) and youth have been found to have lower levels of ART adherence and engagement in HIV care. ${ }^{11-14}$ For example, previous studies have discovered that women and individuals $<30$ years old had higher attrition rates between successive stages of HIV treatment and care, ${ }^{14}$ younger PWID were less likely to receive $\mathrm{ART}^{12}$ and up to $50 \%$ of PWID discontinued ART prematurely. ${ }^{13}$ Hence, there is a need to improve strategies for linking and retaining individuals in HIV care by considering sociodemographic, economic and behavioural vulnerabilities.

\section{Rationale and objectives}

The STOP HIV/AIDS Program Evaluation (SHAPE) study was initiated in 2016 to monitor progress of the provincial programme to optimise testing, treatment and prevention of HIV. The SHAPE study examines determinants of progression along the HIV cascade of care to generate information for addressing ongoing barriers to HIV healthcare. This information will be used to strengthen the implementation of BC's programme for ART expansion. Specific objectives of the SHAPE study are:

1. To monitor the proportion of key groups (Indigenous peoples, youth, PWID and women) who are at different stages along the cascade of care (receiving care, receiving ART, adherent to ART and virologically suppressed) in the context of expanded HIV testing, treatment and care throughout the province.

2. To identify clinical, social and structural determinants of progression along the cascade of care.

3. To assess the impact of community-based organisations, peer support and other supportive services on individuals' HIV-care experiences.

4. To assess the impact of exposure to the STOP HIV/ AIDS Program among PLWH in BC.

5. To assess the beliefs, attitudes and behaviours associated with HIV treatment and care among PLWH in BC and how this impacts their experience in the cascade of care.

\section{COHORT DESCRIPTION}

Between January 2016 and September 2018, PLWH who were BC residents, at least 19 years of age, able to provide informed consent and complete surveys in
English were eligible to enrol in the SHAPE study. Purposive sampling was employed in order to obtain a sample that was representative of key sociodemographic characteristics including age, gender, Indigenous ethnicity, health authority of residence, sexual identity and hepatitis C coinfection. The term 'Indigenous' is used here to describe participants who self-identified as Indigenous in the baseline survey instrument. 'Indigenous' is used to collectively describe the Indigenous peoples of Canada, inclusive of those who identify as "Aboriginal' or First Nations, Métis and Inuit. This term is used while acknowledging the diversity of cultures, languages and traditions that exist among Indigenous Canadians. Recruitment targets were developed by proportionally allotting a subsample size according to rates seen in the population of PLWH across the province. Estimates of the distribution of these characteristics were derived from the Drug Treatment Program (DTP), which distributes ART to all medically eligible residents of $\mathrm{BC}$ and serves as a longitudinal clinical database of all individuals who have been linked to HIV care. Recruitment remained open until there was adequate representation and appropriate power for analytical purposes.

Characteristics of SHAPE participants compared with the population of eligible non-respondents are shown in table 1. Eligible non-respondents were defined as those who (1) accessed HIV care in the DTP during SHAPE's enrolment period (1 January 2016-1 September 2018); (2) were at least 19 years of age on or before 1 September 2018; (3) ever received ART from the DTP and (4) did not participate in SHAPE.

\section{Recruitment methods}

Participants were recruited using a combination of strategies including the following:

1. Community association driven recruitment involved developing partnerships with AIDS service organisations (ASOs) that offer essential resources for PLWH. Outreach and support services provided by ASOs typically relate to medication management, counselling and peer navigation, which are particularly important among individuals who are recently diagnosed and those who face structural barriers to accessing traditional healthcare services. Staff and volunteers at ASOs provided recruitment assistance by promoting the study among their clients through word-of-mouth, advertising on their websites and displaying posters and postcards in their common spaces.

2. In order to reach individuals who do not use ASOs, posters and postcards were placed at clinics that specialise in HIV healthcare across BC, as well as public locations such as notice boards in community centres, coffee shops and libraries. Health clinics serving a large number of PLWH were informed about the study and their staff encouraged to invite eligible patients to participate. Postcards were also included in HIV prescription refill packages that are picked up by patients at pharmacies throughout the province. 
Table 1 Comparison of SHAPE cohort participants with eligible non-respondents who were enrolled in the Drug Treatment Program

\begin{tabular}{|c|c|c|c|}
\hline $\begin{array}{l}\text { Demographic } \\
\text { variables }\end{array}$ & $\begin{array}{l}\text { SHAPE } \\
\text { participants } \\
(\mathrm{n}=644), \mathrm{n}(\%)\end{array}$ & $\begin{array}{l}\text { Eligible non- } \\
\text { respondents } \\
(\mathrm{n}=7737), \mathrm{n}(\%)\end{array}$ & P value \\
\hline Age at baseline* & & & $<0.001$ \\
\hline$<30$ & $25(4)$ & $313(4)$ & \\
\hline $30-<40$ & $92(14)$ & $1078(14)$ & \\
\hline $40-<50$ & $184(29)$ & $1718(22)$ & \\
\hline$\geq 50$ & 343 (53) & $4628(60)$ & \\
\hline Gender & & & $<0.001$ \\
\hline Women & $139(22)$ & $1294(17)$ & \\
\hline Men & $496(77)$ & 6394 (83) & \\
\hline Other & $9(1)$ & $49(1)$ & \\
\hline Ethnicity & & & $<0.001$ \\
\hline Caucasian & 467 (73) & 3012 (63) & \\
\hline Indigenous & $101(16)$ & $674(14)$ & \\
\hline Asian & $18(3)$ & 429 (9) & \\
\hline $\begin{array}{l}\text { African, } \\
\text { Caribbean and } \\
\text { Black }\end{array}$ & $4(1)$ & $240(5)$ & \\
\hline Other & $54(8)$ & $428(9)$ & \\
\hline Missing value & - & 2954 & \\
\hline $\begin{array}{l}\text { History of } \\
\text { injection drug } \\
\text { use }\end{array}$ & $273(42)$ & $2080(33)$ & $<0.001$ \\
\hline Missing value & 96 & 1382 & \\
\hline $\begin{array}{l}\text { Gay, bisexual or } \\
\text { other MSM }\end{array}$ & $368(57)$ & $3089(52)$ & 0.01 \\
\hline Missing value & - & 1776 & \\
\hline
\end{tabular}

*As of study enrolment date for SHAPE participants; as of 1 September 2018 for eligible non-respondents.

MSM, men who have sex with men; SHAPE, Seek and Treat for Optimal Prevention of HIV/AIDS Program Evaluation.

3. A study website was developed to provide information about the study to participants, health workers and ASO staff. The website includes information on participant eligibility, research aims, data collection procedures, ethics and consent processes, contact information and study results. Participants may access the study surveys via a secure link on the website.

4. Paid online advertisements were placed on Craigslist and social networking websites and mobile apps including Facebook, Grindr and Scruff.

\section{Cohort characteristics}

A total of 644 eligible participants were recruited, of whom 139 (22\%) identified as female; $101(16 \%)$ self-reported Indigenous ethnicity; 368 (57\%) identified as gay, bisexual or other men who have sex with men (gbMSM) and $273(42 \%)$ reported a history of injection drug use

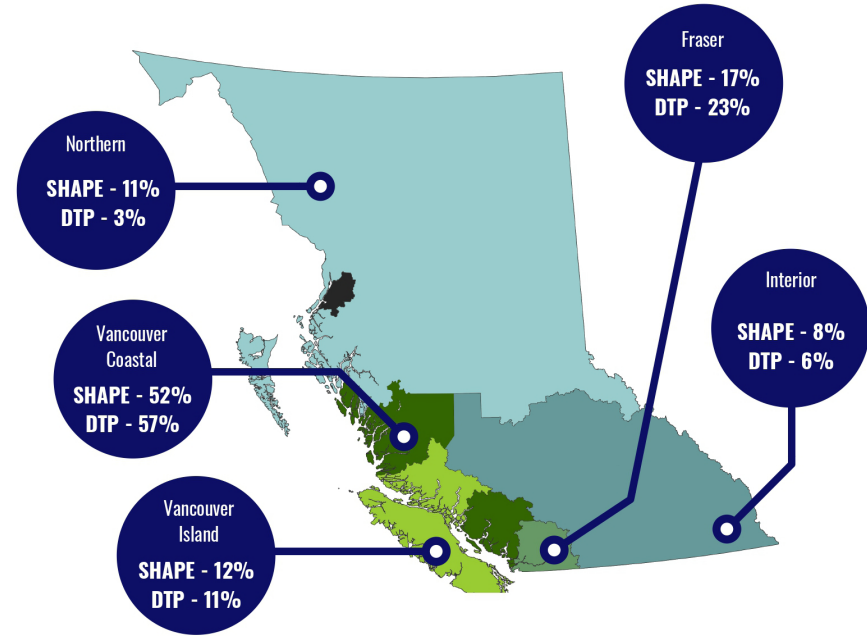

Figure 1 SHAPE cohort composition versus total population of people living with HIV (PLWH) in British Columbia (BC), by $B C$ health authority. Total population of PLWH in BC is based on those enrolled in the DTP who met the SHAPE cohort eligibility criteria, but were not enrolled in the study. DTP, Drug Treatment Program; SHAPE, Seek and Treat for Optimal Prevention of HIV/AIDS Program Evaluation.

(IDU) (see table 1). The median age of SHAPE participants at time of study enrolment was 51 (Q1-Q3: 43-57). Participants had been diagnosed with HIV for a median of 15 years prior to study enrolment (Q1-Q3: 8-21), and median years from first ART date to enrolment was 7 (Q1Q3: 4-12). P values evaluated differences between SHAPE participants and eligible non-respondents in the DTP. $\chi^{2}$ and Fisher's exact test were used for categorical variables and Wilcoxon rank-sum test for continuous variables.

As shown in figure 1, SHAPE participants were enrolled from each health authority in the province. Health authorities are responsible for delivering health services to the population residing within corresponding geographic regions of the province. The majority of PLWH in the province reside in Vancouver Coastal Health (VCH) authority, where BC's most populous city, Vancouver, is located. Health authorities outside of VCH include both urban and non-urban communities, but tend to be less densely populated and have a lower concentration of HIV-related services. Based on emerging research indicating that PLWH who reside in non-urban areas face increased vulnerability at each stage of the HIV cascade of care ${ }^{15}$ we hypothesised that individuals outside of VCH may encounter unique barriers to accessing HIV services. Hence, it was a priority for the SHAPE research team to engage participants throughout $\mathrm{BC}$, and in particular, to ensure representativeness of regions that have previously been under-represented in research.

\section{Data collection and follow-up}

Participants completed a baseline survey and throughout the course of the study will complete two follow-up surveys, 18 months apart, collecting information concerning their HIV care experiences. Each survey takes approximately 1 hour to complete, and participants are compensated 
$\$ 30$ per survey for their time and expertise. Participants are offered the option of completing an online self-administered survey, or being interviewed by a peer research associate (PRA) by phone or in-person. These options were established to minimise financial, physical and social barriers to participation for individuals across the province.

Most participants $(60.3 \%)$ chose to complete the baseline survey online, whereas $34.8 \%$ completed the survey in-person and $5.0 \%$ completed the survey over the phone. Of participants that responded to a supplemental question regarding their recruitment into the study $(n=198)$, $39.9 \%$ were recruited through ASOs and peer navigators, $20.7 \%$ heard about the study from physicians or healthcare workers, $13.1 \%$ responded to an informational postcard received with their HIV medication prescription and the remainder were recruited via clinic bulletin boards, social media or friends and family.

Prior to enrolling in the study, and before commencing each follow-up survey, participants consented to use of their anonymised survey data and linked clinical records, held by the BC Ministry of Health, for SHAPE research. Those who self-administered the survey online provided consent electronically via the study website. For phone and in-person interviews, consent was given verbally or in writing with assistance from a PRA or other study staff member. Participants also agreed to being contacted at a later date for follow-up or for clarification regarding any missing survey information.

\section{Surveys}

The SHAPE baseline survey is comprised of the following sections: (1) sociodemographics, (2) current health and medical history, (3) HIV testing and diagnosis experiences, (4) linkage to care, (5) treatment, (6) retention in care and resiliency and (7) awareness and experience of the STOP HIV/AIDS Program. Development of the survey tool involved a literature review for the purpose of identifying key topic areas as well as variables and validated scales for inclusion in the survey. Selected scales include: a partial Household Food Security Survey Module, ${ }^{16}$ Short Form-6D for measuring health-related quality of life, ${ }^{17}$ Drug Abuse Screening Test, ${ }^{18}{ }^{19}$ Alcohol Use Disorders Identification Test-Concise (AUDIT-C), ${ }^{20}{ }^{21}$ Centre for Epidemiologic Studies Depression Scale (CES-D 10), ${ }^{2223}$ Everyday Discrimination Scale, ${ }^{24} 25$ 10-item Berger HIV Stigma Scale, ${ }^{26}{ }^{27}$ HIV Treatment Adherence SelfEfficacy Scale (HIV-ASES), ${ }^{28}$ Antiretroviral Medication Attitude Scale,$^{29}$ Continuity of Care Scale ${ }^{30}$ and Medical Outcomes Study Social Support Survey (MOS-SSS). ${ }^{31-33}$ Follow-up surveys also examine resiliency and HIV disclosure concerns using the Resilience Scale ${ }^{34} 35$ and disclosure sub-scale of HIV/AIDS Quality of Life Scale, ${ }^{36} 37$ respectively.

Surveys were pretested and improved on with the expertise of PRAs, followed by a pilot phase in which additional community members assessed the survey for appropriateness and sensitivity. Participants are encouraged to provide feedback so that further improvements can be made to future surveys.

\section{Linkages to clinical data}

The SHAPE study benefits immensely from data linkage with the DTP. Anyone prescribed ART in the province of BC is automatically enrolled in the DTP, thereby enabling longitudinal follow-up of health records and laboratory results related to HIV treatment and virological outcomes. Through the DTP database, the SHAPE study is able to link participant survey responses with routine clinical data collection such as CD4 cell counts, viral load testing, specific ART regimen and changes, adherence and the provincial vital statistics registry. This linkage also enables the SHAPE research team to compare demographics and clinical indicators between SHAPE participants and non-participants.

\section{Patient and public involvement}

In accordance with GIPA/MIPA (Greater/Meaningful Involvement of PLWH) principles, PLWH are meaningfully involved in all phases of the SHAPE study from planning to data collection, analysis and knowledge dissemination. ${ }^{38}$ PRAs, who share lived experiences with study participants and are trained in research methods, facilitate recruitment and interview study participants. While past studies in the field of HIV have at times been limited by lower levels of community involvement outside of the process of the data collection phase ${ }^{39}{ }^{40}$ SHAPE PRAs are involved in identifying research priorities and questions, developing and evaluating data collection tools, analysing data and sharing findings. Knowledge dissemination strategies prioritise bringing findings back to communities and fostering dialogue that may guide research direction and further enhance collaboration.

\section{FINDINGS TO DATE}

The SHAPE study collects comprehensive data on social determinants of health and individual attitudes, experiences and behaviours that may impact HIV treatment outcomes. Table 2 depicts the SHAPE cohort by sociodemographic, health and behavioural characteristics.

Since the SHAPE cohort completed enrolment in September 2018, several studies have used baseline survey data to examine social determinants of progression along the cascade of care. One recently presented preliminary analysis used baseline survey responses in conjunction with longitudinal clinical data to assess the relationship between social support, which was self-reported using the MOS-SSS, ${ }^{33}$ and engagement in HIV treatment. Results from multivariable logistic regression modelling demonstrated that social support is protective against interruptions in ART. After adjustment for known confounders, each $10 \%$ increase in MOS-SSS score was found to reduce the likelihood of experiencing ART interruptions by $16 \%{ }^{41}$ Other recent studies include characterisation of the distribution of HIV-related stigma among 
Table 2 Characteristics of SHAPE participants $(n=644)$ at time of study enrolment

\begin{tabular}{lc}
\hline Variable & $\begin{array}{l}\text { Count, } \mathbf{n}(\%) \text { or median } \\
\text { (Q1-Q3) }\end{array}$ \\
\hline Education level & \\
Less than high school & $147(23)$ \\
Completed high school & $193(30)$ \\
Greater than high school & $302(47)$
\end{tabular}

Sexual orientation

$\begin{array}{lr}\text { Heterosexual } & 240(37) \\ \text { Gay or lesbian } & 315(49) \\ \text { Other } & 89(14)\end{array}$

\begin{tabular}{lc}
$\begin{array}{l}\text { Annual income for year prior } \\
\text { to enrolment (\$) }\end{array}$ & $16800(13200-30720)$ \\
\hline $\begin{array}{l}\text { Currently employed } \\
\text { Food insecure* }\end{array}$ & $326(45)$ \\
$\begin{array}{l}\text { Currently receiving housing } \\
\text { subsidy }\end{array}$ & $232(36)$ \\
\hline
\end{tabular}

\begin{tabular}{|c|c|}
\hline \multicolumn{2}{|l|}{ Incarceration history } \\
\hline $\begin{array}{l}\text { Incarcerated within the } \\
\text { past year }\end{array}$ & $19(3)$ \\
\hline $\begin{array}{l}\text { Yes, but not within the past } \\
\text { year }\end{array}$ & $209(32)$ \\
\hline Never incarcerated & $416(65)$ \\
\hline \multicolumn{2}{|l|}{ History of homelessness } \\
\hline Currently homeless & $27(4)$ \\
\hline $\begin{array}{l}\text { Yes, in the past year but } \\
\text { not now }\end{array}$ & 65 (10) \\
\hline $\begin{array}{l}\text { Yes, but not in the past } \\
\text { year }\end{array}$ & $231(36)$ \\
\hline Never homeless & $321(50)$ \\
\hline Mental illness diagnosis, ever & $341(53)$ \\
\hline CES-D 10 (depression) score & $9(5-16)$ \\
\hline Significantly depressed $†$ & $312(48)$ \\
\hline $\begin{array}{l}\text { MOS-SSS (social support) } \\
\text { scoreł }\end{array}$ & $65(42-86)$ \\
\hline AUDIT-C (alcohol use) score & $2(0-5)$ \\
\hline Hazardous alcohol use§ & 247 (38) \\
\hline HIV stigma scoreף & $48(33-63)$ \\
\hline
\end{tabular}

Use of supportive services since HIV diagnosis

$\begin{array}{lc}\text { Peer navigation } & 225(37) \\ \text { ASOs } & 451(71) \\ \begin{array}{l}\text { Food bank/meal } \\ \text { programme }\end{array} & 269(44) \\ \text { Other } & 221(36) \\ \text { Clinical variables } & \\ \text { Hepatitis C coinfection } & 215(33) \\ \text { Years since HIV diagnosis } & 15(8-21)\end{array}$

Continued
Table 2 Continued

\begin{tabular}{lc} 
Variable & $\begin{array}{l}\text { Count, } \mathbf{n}(\%) \text { or median } \\
\text { (Q1-Q3) }\end{array}$ \\
\hline $\begin{array}{l}\text { Viral load testing rate } \\
\text { (tests/year during year prior } \\
\text { to baseline }{ }^{\star \star} \text { ) }\end{array}$ & $4(3-5)$ \\
Years on ART & \\
ART interruption ever & $7(4-12)$ \\
\hline
\end{tabular}

*Food insecure was defined as often or sometimes unable to afford to eat balanced meals in the past 12 months.

†The CES-D 10 measures depressive symptomology using a shortened 10-item scale that has been validated for use among $\mathrm{PLWH}$ in $\mathrm{BC} .^{22}$ The possible range is $0-30$ with scores $\geq 10$ indicating the presence of significant depressive symptoms. $\ddagger$ The MOS-SSS is an overall support index calculated by transforming scores from a 19-item scale to have a range of $0-100$; higher scores indicate greater social support. Instructions for scoring and interpreting the MOS-SSS are available at www.rand. org/health-care/surveys_tools/mos/social-support.html.

$\S$ This validated and shortened version of the AUDIT scale has a possible range of $0-12$ with scores $\geq 4$ for men and $\geq 3$ for women indicating hazardous alcohol use.

IHIV stigma scores have been reparametrised to have a range of 0-100 with higher scores indicating higher levels of perceived stigma. Scores are calculated based on a shortened and validated 10 -item version of the scale, which includes items from all four subscales of the original 40 -item scale: personalised stigma, disclosure concerns, negative self-image and concern with public attitudes. $^{27}$

${ }^{* *}$ As of study enrolment date for SHAPE participants. ††ART interruption defined as 90 days or longer off ART among individuals who have ever initiated treatment. A limitation of this assessment is that we lack information concerning clinical trial status of SHAPE participants and non-respondents, which may inflate the appearance of treatment interruptions in our data. ART, antiretroviral therapy; ASO, AIDS service organisation; AUDIT-C, Alcohol Use Disorders Identification Test-Concise; BC, British Columbia; CES-D 10, Centre for Epidemiologic Studies Depression Scale; MOS-SSS, Medical Outcomes Study Social Support Survey; SHAPE, Seek and Treat for Optimal Prevention of HIV/AIDS Program Evaluation.

individuals accessing ART, and a prospective analysis of changes in clinical outcomes-including viral rebound, ART interruption and sustained ART adherence-since study enrolment. Respective results indicated that age, city size, IDU experience, violence and mental health disorder diagnosis are independently associated with HIV-related stigma, ${ }^{42}$ and that despite few occurrences of viral rebound or less the optimal ART adherence among SHAPE participants, disparities exist based on key characteristics related to age, ethnicity, geography, socioeconomic status and incarceration, among other facets of structural marginalisation. ${ }^{43}$

In addition, preliminary findings disseminated via conference presentations describe prevalence and predictors of viral suppression in the SHAPE cohort. Our research indicates that despite high levels of engagement along the cascade of care among SHAPE participants ( $>80 \%$ of participants at each stage) (figure 2 ), inequities in treatment outcomes persist among certain vulnerable 


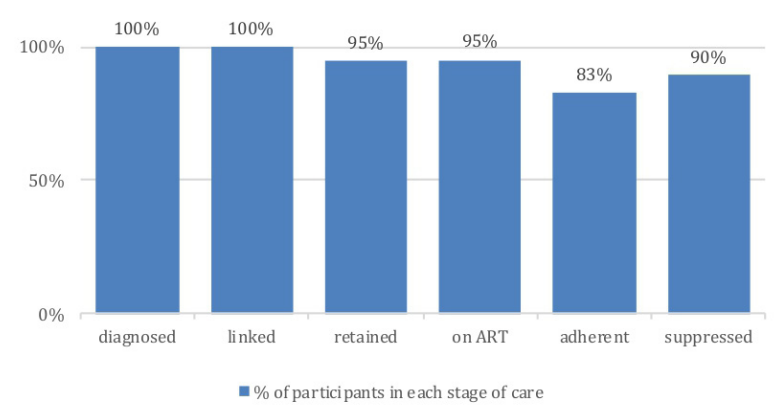

Figure 2 HIV cascade of care among Seek and Treat for Optimal Prevention of HIV/AIDS Program Evaluation participants at time of study enrolment $(n=644)$. 'Diagnosed': first instance of detectable viral load, a reported AIDSdefining illness or ART dispensation. 'Linked': first instance of HIV-related service (viral load/CD4 test or ART dispensation) $\geq 30$ days following HIV diagnosis date. 'Retained': viral load/CD4 test or at least two ART dispensations $\geq 3$ months apart within 12 months prior to baseline survey. 'On ART': at least two ART dispensations $\geq 3$ months apart within 12 months prior to baseline survey. 'Adherent': $>80 \%$ adherence within 12 months prior to baseline survey. 'Suppressed': undetectable viral load ( $<200$ copies $/ \mathrm{mL}) \geq 3$ months within 12 months prior to baseline survey. ART, antiretroviral therapy.

groups. Among PLWH in BC, younger adults, individuals with a history of IDU and those who are currently homeless are at greater risk for failing to achieve viral suppression. ${ }^{44}$ Moreover, age and HIV risk type were identified as determinants of time to suppression, with younger age and identification with a risk group other than gbMSM predicting longer time between initiation of ART and viral suppression. ${ }^{45}$ These findings corroborate previous research on determinants of viral suppression, ${ }^{46-51}$ and suggest the need for targeted supports to address health disparities among PLWH in BC.

Future research will seek to quantify differences in clinical outcomes and experiences of accessing HIV care between SHAPE participants who were diagnosed with HIV prior to and during the era of the STOP HIV/ AIDS Program. Studies will also continue to examine how engagement in care evolves over time and to identify barriers and facilitators for promoting equitable access to HIV treatment and care. These quantitative analyses will be complimented by a qualitative research project, which is currently in the formative and planning stage. Qualitative work will consist of two components: 1) semi-structured interviews of healthcare providers and PLWH that take a strength-based approach to examining experiences of engagement and re-engagement in HIV treatment; and 2) supporting the development of an Indigenous-led research programme that explores the knowledge and experiences of Indigenous peoples living with HIV.
Knowledge dissemination strategies used by the SHAPE research team include traditional avenues such as academic conferences and manuscripts, and community-based knowledge translation and exchange activities. Methods of bringing research back to communities include presentations and discussions held at our research sites, and producing plain language summaries; newsletters and information sheets.

\section{STRENGTHS AND LIMITATIONS}

The SHAPE cohort provides a unique source of information on HIV care experiences among PLWH in BC. The comprehensive survey tool allows for quantitative assessment of behaviours, beliefs and attitudes related to HIV testing, treatment and care, which is further contextualised by social, structural and medical factors reported by participants. Moreover, linkage of survey responses with longitudinal clinical data allows for analysis of the impact of HIV care experiences on long-term cascade of care outcomes, such as experiences of HIV treatment interruptions, changes in ART regimens, sustained viral suppression or viral rebound.

Purposive sampling methods were used to ensure that findings would be representative of the experiences of PLWH throughout BC who have diverse sociodemographic and clinical characteristics. An important strength of the study is the representativeness that was achieved by geographic region, which was defined by health authority of residence. However, challenges were experienced in reaching certain enrolment targets. Younger adults aged 19-29 years and mid-higher income groups were difficult to recruit. Moreover, SHAPE is a sample of individuals with high levels of engagement in care at the time of baseline interview; therefore, PLWH who face the most pervasive barriers to accessing HIV treatment and care may be under-represented.

Acknowledgements First and foremost, the SHAPE research team would like to acknowledge the contribution of all the participants who shared their knowledge and time, and who entrusted us with their personal experiences of living with HIV and accessing care. The SHAPE team is also thankful for the cooperation of our community partners, especially those research sites that assisted us in engaging with participants. Further to this, we would like to acknowledge and thank the peer research associates, study coinvestigators and knowledge users for their ongoing contributions to this project.

Collaborators For further information on the SHAPE study, please contact the principal investigator, RB (rbarrios@cfenet.ubc.ca) or the study coordinator, CT ( ctam@cfenet.ubc.ca). We welcome feedback and ideas, including proposals for collaboration on data analyses or knowledge translation and exchange activities.

Contributors RB conceptualised and established the SHAPE study. AB conceptualised and drafted the present manuscript with contributions from PS, LW, BB, KS, DMM, TW and CT. SG and TW collected data, and LW conducted statistical analyses. All authors critically reviewed and approved the manuscript.

Funding This work received funding from the BC Centre for Excellence in HIV/AIDS and the BC Ministry of Health.

Map disclaimer The depiction of boundaries on this map does not imply the expression of any opinion whatsoever on the part of $B M J$ (or any member of its group) concerning the legal status of any country, territory, jurisdiction or area or of its authorities. This map is provided without any warranty of any kind, either express or implied. 
Competing interests None declared.

Patient and public involvement Patients and/or the public were involved in the design, or conduct, or reporting, or dissemination plans of this research. Refer to the Methods section for further details.

Patient consent for publication Not required.

Ethics approval Ethical approval for the SHAPE study was obtained from the University of British Columbia/Providence Health Care research ethics board (REB number: H15-01807).

Provenance and peer review Not commissioned; externally peer reviewed.

Data availability statement The data for this study cannot be made available due to restrictions from research ethics and contractual obligations.

Open access This is an open access article distributed in accordance with the Creative Commons Attribution Non Commercial (CC BY-NC 4.0) license, which permits others to distribute, remix, adapt, build upon this work non-commercially, and license their derivative works on different terms, provided the original work is properly cited, appropriate credit is given, any changes made indicated, and the use is non-commercial. See: http://creativecommons.org/licenses/by-nc/4.0/.

ORCID iD

Andrea Bever http://orcid.org/0000-0001-7084-4733

\section{REFERENCES}

1 SMART Study Group, El-Sadr WM, Grund B, et al. Risk for opportunistic disease and death after reinitiating continuous antiretroviral therapy in patients with HIV previously receiving episodic therapy: a randomized trial. Ann Intern Med 2008;149:289-99.

2 Lima VD, Eyawo O, Ma $\mathrm{H}$, et al. The impact of scaling-up combination antiretroviral therapy on patterns of mortality among HIV-positive persons in British Columbia, Canada. J Int AIDS Soc 2015;18:20261.

3 Lima VD, Lourenço L, Yip B, et al. Aids incidence and AIDS-related mortality in British Columbia, Canada, between 1981 and 2013: a retrospective study. Lancet HIV 2015;2:e92-7.

4 Montaner JSG, Hogg R, Wood E, et al. The case for expanding access to highly active antiretroviral therapy to curb the growth of the HIV epidemic. Lancet 2006;368:531-6.

5 Cohen MS, Chen YQ, McCauley M, et al. Prevention of HIV1 infection with early antiretroviral therapy. N Engl J Med 2011;365:493-505.

6 Montaner JSG, Lima VD, Barrios R, et al. Association of highly active antiretroviral therapy coverage, population viral load, and yearly new HIV diagnoses in British Columbia, Canada: a population-based study. Lancet 2010;376:532-9.

7 Wood E, Kerr T, Marshall BDL, et al. Longitudinal community plasma HIV-1 RNA concentrations and incidence of HIV-1 among injecting drug users: prospective cohort study. BMJ 2009;338:b1649.

8 WHO Department of HIV/AIDS, UNAIDS. The treatment 2.0 framework for action: catalysing the next phase of treatment, care and support, 2011

$9 \mathrm{Bc}$ centre for excellence in HIV/AIDS. B.C. launches province-wide expansion of stop HIVIAIDS $®$ program, 2013.

10 Heath K, Samji H, Nosyk B, et al. Cohort profile: seek and treat for the optimal prevention of HIV/AIDS in British Columbia (stop HIV/ AIDS bc). Int J Epidemiol 2014;43:1073-81.

11 Wood E, Kerr T, Palepu A, et al. Slower uptake of HIV antiretroviral therapy among Aboriginal injection drug users. $J$ Infect 2006;52:233-6.

12 Strathdee SA, Palepu A, Cornelisse PG, et al. Barriers to use of free antiretroviral therapy in injection drug users. JAMA 1998;280:547-9.

13 Krüsi A, Wood E, Montaner J, et al. Social and structural determinants of HAART access and adherence among injection drug users. Int J Drug Policy 2010;21:4-9.

14 Lourenço L, Colley G, Nosyk B, et al. High levels of heterogeneity in the HIV cascade of care across different population subgroups in British Columbia, Canada. PLoS One 2014;9:e115277.

15 Schafer KR, Albrecht H, Dillingham R, et al. The continuum of HIV care in rural communities in the United States and Canada. JAIDS Journal of Acquired Immune Deficiency Syndromes 2017;75:35-44.

16 Health Canada. Canadian Community Health Survey, Cycle 2.2, Nutrition (2004). In: Income-Related household food security in Canada, 2007.
17 Feeny D, Wu L, Eng K. Comparing short form 6D, standard gamble, and health Utilities index mark 2 and mark 3 utility scores: results from total hip arthroplasty patients. Qual Life Res 2004;13:1659-70

18 Yudko E, Lozhkina O, Fouts A. A comprehensive review of the psychometric properties of the drug abuse screening test. J Subst Abuse Treat 2007;32:189-98.

19 Skinner HA. The drug abuse screening test. Addict Behav 1982;7:363-71.

20 Saunders JB, Aasland OG, Babor TF, et al. Development of the Alcohol Use Disorders Identification Test (AUDIT): WHO Collaborative Project on Early Detection of Persons with Harmful Alcohol Consumption--II. Addiction 1993;88:791-804.

21 Conigrave KM, Saunders JB, Reznik RB. Predictive capacity of the audit questionnaire for alcohol-related harm. Addiction 1995;90:1479-85.

22 Zhang W, O'Brien N, Forrest Jl, et al. Validating a shortened depression scale (10 item CES-D) among HIV-positive people in British Columbia, Canada. PLoS One 2012;7:e40793.

23 Radloff LS. The CES-D scale: a self-report depression scale for research in the general population. Applied Psychological Measurement 1977;1:385-401.

24 Williams DR, Yan Yu, Jackson JS, Yu Y, et al. Racial differences in physical and mental health: socio-economic status, stress and discrimination. J Health Psychol 1997;2:335-51.

25 Krieger N, Smith K, Naishadham D, et al. Experiences of discrimination: validity and reliability of a self-report measure for population health research on racism and health. Soc Sci Med 2005;61:1576-96.

26 Berger BE, Ferrans CE, Lashley FR. Measuring stigma in people with HIV: psychometric assessment of the HIV stigma scale. Res Nurs Health 2001;24:518-29.

27 Wright K, Naar-King S, Lam P, et al. Stigma scale revised: reliability and validity of a brief measure of stigma for HIV+ youth. $J$ Adolesc Health 2007;40:96-8.

28 Johnson MO, Neilands TB, Dilworth SE, et al. The role of selfefficacy in HIV treatment adherence: validation of the HIV treatment adherence self-efficacy scale (HIV-ASES). J Behav Med 2007:30:359-70.

29 Viswanathan $\mathrm{H}$, Anderson R, Thomas J. Evaluation of an antiretroviral medication attitude scale and relationships between medication attitudes and medication nonadherence. AIDS Patient Care STDS 2005;19:306-16.

30 Dolovich LR, Nair KM, Ciliska DK, et al. The diabetes continuity of care scale: the development and initial evaluation of a questionnaire that measures continuity of care from the patient perspective. Health Soc Care Community 2004;12:475-87.

31 Gjesfjeld CD, Greeno CG, Kim KH. A confirmatory factor analysis of an abbreviated social support instrument: the MOS-SSS. Res Soc Work Pract 2008;18:231-7.

32 Stewart AL, Ware JE, Ware Jr JE. Measuring functioning and wellbeing: the medical outcomes study approach. duke university Press, 1992.

33 Sherbourne CD, Stewart AL. The mos social support survey. Soc Sci Med 1991;32:705-14.

34 Wagnild GM, Young HM. Development and psychometric evaluation of the resilience scale. J Nurs Meas 1993;1:165-78.

35 Wagnild GM. The resilience scale user's guide: for the US English version of the resilience scale TM and the 14-Item resilience scale TM (RS-14 TM. Resilience center, 2009.

36 Holmes WC, Shea JA. Performance of a new, HIV/AIDS-targeted quality of life (HAT-QoL) instrument in asymptomatic seropositive individuals. Qual Life Res 1997;6:561-71.

37 Holmes WC, Shea JA. A new HIV/AIDS-targeted quality of life (HATQoL) instrument: development, reliability, and validity. Med Care 1998;36:138-54.

38 Closson K, McNeil R, McDougall P, et al. Meaningful engagement of people living with HIV who use drugs: methodology for the design of a peer research associate (PRA) hiring model. Harm Reduct $J$ 2016;13:26

39 Travers R, Wilson MG, Flicker S, et al. The greater involvement of people living with AIDS principle: theory versus practice in Ontario's HIV/AIDS community-based research sector. AIDS Care 2008;20:615-24.

40 Flicker S, Savan B, Kolenda B, et al. A snapshot of communitybased research in Canada: who? what? why? how? Health Educ Res 2008;23:106-14.

41 Wesseling T, Bever A, McLinden T, et al. Social support is associated with lower likelihood of HIV treatment interruptions in British Columbia, Canada. 28th annual Canadian conference on HIVIAIDS research. Saskatoon, Canada, 2019: 9-12. 
42 Bever A, Grieve S, Wang L, et al. Factors associated with HIV-related stigma among individuals accessing antiretroviral therapy in British Columbia, Canada. Vancouver, Canada: STI \& HIV 2019 World Congress, 2019: 14-17.

43 Bever A, Bingham B, McLinden T, et al. Prospective changes in clinical outcomes among people living with HIV who have previously achieved virologic suppression. Saskatoon, Canada: 28th Annual Canadian Conference on HIV/AIDS Research, 2019: 9-12.

44 Bever A, Salters KA, Wang C, et al. Determinants of viral suppression among people living with HIV in British Columbia, Canada. In: Preliminary findings from the shape study. Vancouver, British Columbia: 27th Annual Canadian Conference on HIV/AIDS Research, 2018: 26-9.

45 Bever A, Salters KA, McLinden T, et al. Prevalence and predictors of viral suppression among people living with HIV in British Columbia, Canada. In: Findings from the shape study. Amsterdam, the Netherlands: 22nd International AIDS Conference, 2018: 23-7.

46 Cescon AM, Cooper C, Chan K, et al. Factors associated with virological suppression among HIV-positive individuals on highly active antiretroviral therapy in a multi-site Canadian cohort. HIV Med 2011;12:352-60.

47 Knowlton A, Arnsten J, Eldred L, et al. Individual, interpersonal, and structural correlates of effective HAART use among urban active injection drug users. J Acquir Immune Defic Syndr 2006;41:486-92.

48 Milloy M-J, Kerr T, Bangsberg DR, et al. Homelessness as a structural barrier to effective antiretroviral therapy among HIVseropositive illicit drug users in a Canadian setting. AIDS Patient Care STDS 2012;26:60-7.

49 Mujugira A, Celum C, Tappero JW, et al. Younger age predicts failure to achieve viral suppression and virologic rebound among HIV-1infected persons in serodiscordant partnerships. AIDS Res Hum Retroviruses 2016;32:148-54.

50 Muthulingam D, Chin J, Hsu L, et al. Disparities in engagement in care and viral suppression among persons with HIV. JAIDS Journal of Acquired Immune Deficiency Syndromes 2013;63:112-9.

51 Tanner Z, Lachowsky N, Ding E, et al. Predictors of viral suppression and rebound among HIV-positive men who have sex with men in a large multi-site Canadian cohort. BMC Infect Dis 2016;16:590. 